\title{
Oral Therapeutic Vaccine V3-X
}

National Cancer Institute

\section{Source}

National Cancer Institute. Oral Therapeutic Vaccine V3-X. NCI Thesaurus. Code C148144.

An orally bioavailable therapeutic vaccine consisting of the tumor-associated antigen

(TAA) oligosaccharide antigen sialyl Lewis A (CA19-9; sialylated Lewis A antigen;

carbohydrate antigen 19-9; cancer antig en 19-9), with potential immunostimulating and

antineoplastic activities. Upon oral administration, oral therapeutic vaccine V3-X induces a

cytotoxic T-lymphocyte ( $C T L$ )-mediated immune response ag ainst tumor cells

expressing CA19-9. CA19-9 is an antigen that is overexpressed in a variety of cancer cell

types, and plays a key role in tumor cell survival and metastasis. 